\title{
Editorial
}

\section{Special Issue: Aspects of Game Theory and Institutional Economics}

\section{Wolfram Elsner *, Torsten Heinrich, Henning Schwardt and Claudius Gräbner}

Structural Research and Policy Division, (iino) Institute for Institutional and Innovation Economics, Department of Business Studies and Economics, University of Bremen, Hochschulring 4, D-28359 Bremen, Germany; E-Mails: torsten.heinrich@uni-bremen.de (T.H.); schwardt@uni-bremen.de (H.S.); graebnerc@uni-bremen.de (C.G.)

* Author to whom correspondence should be addressed; E-Mail: welsner@uni-bremen.de; Tel.: +49-421-218-66610.

Received: 30 July 2014 / Accepted: 5 August 2014 / Published: 4 September 2014

\section{Towards a Complexity Economics}

Classical economists from Adam Smith to Thomas Malthus and to Karl Marx have considered the importance of direct interdependence and direct interactions for the economy. This was even more the case for original institutionalist thinkers such as Thorstein Veblen, John Commons, and Clarence Ayres. In their writings, direct interdependence, interactions (or transactions) among agents, with all beneficial and with all problematic consequences, took center stage in economic analysis. Why, for instance, do people adhere to a particular new fashion or trend? Because others do, after eminent people, wealthy people, the "leisure class" (T. Veblen), have made it a symbol for status. The new fashion, however, ceases to serve as such a symbol once too many people follow it. The constant effort put into following trends and adopting fashion turns out to be a social dilemma, driven by Veblenian instincts, such as invidious distinction in predatory societies, conspicuous consumption and emulation.

The general issues of herd behavior and myopic individualistic decision making, both under opacity and highly bounded rationality in complex systems, and both possibly carrying the problem of negative unintended consequences for the economy as a whole, for society and the natural commons, have taken center stage again in the global financial crisis of 2007, which still lingers around as the "Great Recession".

The "representative agent" of the economic mainstream's theoretical core model, whose decisions may simplistically be summed up into the aggregates of the related macroeconomics, has most overtly failed to enable economists to even realize inherent tendencies towards crises in real-world complex systems, based on intricate common and collective decision structures. 
Of course, both classical political economy and original institutional economics lacked the formal methods to describe intricate interdependencies and decision structures in exact and mathematical terms - even if they wanted to (while some of them have been rather critical with respect to any formalism). In particular, they could not employ modern game theory, evolutionary algorithms, or agent-based simulation. Today, we can. As it happens, these methods are much better suited to describe classical and evolutionary-institutionalist theories and complex economies of interactive agents than, for instance, vector fields and nonlinear optimization that were en vogue in economics at the time of Veblen's writings. The ex-post aggregates that emerge in simulations show one instance in which analytical advantages can in fact be realized utilizing such methods.

Among economists, the interest in these approaches has continued to grow. Making classical and evolutionary-institutional theories accessible to formal methods, and in this way even shedding new light on different aspects of traditional subjects has been at the core of a new development in economics - using game theory, agent-based modelling, simulation, and lab experiments to tackle complex dynamic, evolutionary, and institutional phenomena. Elinor Ostrom, well-known for her experimental as well as theoretical and field research on the commons and social dilemmas, received the Nobel memorial prize in 2009, but many other scholars (including a number of other Nobel laureates) have been active in this field as well. In fact, such complexity economics has apparently become a new vanishing point of the economics discipline, at least in research (albeit not in textbooks and academic mass education).

\section{The Contributions to this Special Issue}

The current Special Issue of "games" is an attempt to highlight some recent work in this field and to bring some papers of the field together in a single publication.

While two of the papers (by Wolfgang Radax, Bernhard Rengs, and Manuel Wäckerle, and that of Jürgen Fleiß and Stefan Palan) in this issue pursue the question of the emergence and coevolution of institutions and hierarchy, a third paper (by Tassos Patokos) analyzes algorithms of strategy change in evolutionary game models, and the fourth paper (by Alexander Field) takes a historical (history-ofeconomic-thought) point of view on the development of game theory during the cold war.

Radax et al. ("An Agent-Based Model of Institutional Life-Cycles") offer an application of an agent-based simulation on the formation and development of institutions. They consider the development of institutions in a population of agents playing repeated prisoners' dilemma games. The paper models institutions as voluntary associations of agents with cooperation enforced by a leader. Simulations show three sharply differing possible scenarios: universal institutionalized cooperation, universal defection with stable institutions of internal cooperation, and a scenario with non-trivial institutional life-cycles. In an elegant way, the authors connect the paper metaphorically and practically to Ilya Prigogine's and Stuart Kauffman's concepts of complexity as a transition regime between ordered and chaotic states, identifying these three regimes, each with one of the dominant three scenarios they found in their simulation study.

Fleiß and Palan ("Of Coordinators and Dictators: A Public Goods Experiment") consider a similar question with a methodologically different and, in fact, complementary approach. They conducted laboratory experiments and find that human subjects are generally willing - at an overwhelming 
margin - to pay for being part of an institution with enforced cooperation when faced with a social dilemma situation. The context was the production of a public good; agents could freely choose between a setting with voluntary and one with enforced contribution. In their experiments, agents strongly favor enforced contribution even if the randomly selected leader of the institution can exploit her position and free-ride.

Patokos ("Introducing Disappointment Dynamics and Comparing Behaviors in Evolutionary Games: Some Simulation Results") pursues a subject that is of central importance to many evolutionary game theory and replicator models (those with a reassignment of strategies instead of exit and entry): the mode of strategy updating on the part of the agents. He considers three commonly used algorithms, immediate updating in the event of sub-optimal outcomes, updating based on the outcomes of several iterations, and updating based on a threshold outcome-level. Analyzing the algorithms against a number of game structures for evolutionary game theory interaction settings and again with stochastic perturbation, sharply diverging outcomes are found.

Field ("Schelling, von Neumann, and the Event that Didn't Occur"), in a quite different kind of paper, a historical review, discusses the evolution of game theory during the cold war. He argues that the historical standoff confrontation at the edge of a nuclear war had a profound impact on, not only the scholars, but also the ideas, concepts, and methods of game theory itself. While this historical reconstruction of a critical phase of development, application, and identity finding of game theory, may easily be controversial, it offers a number of truly challenging thoughts and reflections that are as original as they are unorthodox — provided, in this case, by an established institutional(ist) game theorist.

\section{An Outlook}

The study of institutions is not a new subject in economics at all. But it has attracted a continuing scholarly interest for decades, and many conceptual, theoretical, and methodological breakthroughs have been accomplished in this field, particularly since the dawn of modern game theory and the use of computers for simulation and economic experiments. The seminal works by Robert Axelrod and Elinor Ostrom are merely two examples. These too were centered on the evolution of institutions in a context of social dilemma situations - a research project that is vigorously continued by the first two papers in this issue. Of course, these efforts must always be accompanied by an equally firm resolution to work on other questions of evolutionary and institutional economics (and beyond); further on methodology and, finally, to critically question the institutional history of both game theory formal methods and evolutionary and institutional economics (on which this issue also contains one paper each).

Bremen, Germany, May 2014

(C) 2014 by the authors; licensee MDPI, Basel, Switzerland. This article is an open access article distributed under the terms and conditions of the Creative Commons Attribution license (http://creativecommons.org/licenses/by/3.0/). 